\title{
Association of the type of counselor with suicidal ideation and suicide attempts: a survey of South Korean adolescents
}

Yunkyung Kim ${ }^{1,2}$, Wonjeong Jeong ${ }^{1,2}$, Jieun Yang ${ }^{1,2}$, Sang Ah Lee ${ }^{1,2}$ and Eun-Cheol Park ${ }^{2,3^{*}}$ (D)

\begin{abstract}
Background: Counseling for adolescents who consider or attempt suicide may help reduce suicide rates. However, the impact of the type of counselor (e.g., father, mother, sibling, friend, teacher, other) on suicidal ideation/suicide attempts remains unclear. Therefore, we examined this association in Korean adolescents.

Methods: Using data from the 2015 Korea Youth Risk Behavior Web-based Survey of 65,485 adolescents, we examined risk factors for suicidal ideation/suicide attempts according to sex using a multiple logistic regression analysis. In a subgroup analysis, we investigated the associations between counselor type and suicidal ideation/suicide attempts stratified by the cause of stress for both sexes.
\end{abstract}

Results: Male participants were less likely to consider suicide when counseled by their mother (odds ratio [OR] 0.80; $95 \%$ confidence interval [Cl] 0.70-0.90) or friend (OR 0.89; $95 \% \mathrm{Cl} 0.80-0.99)$ and to attempt suicide when counseled by a friend (OR $0.74 ; 95 \% \mathrm{Cl} 0.60-0.92)$ than were those who did not receive any counseling. Female participants were less likely to attempt suicide when counseled by their mother (OR 0.66; 95\% $\mathrm{Cl} 0.53-0.82)$ or friends $(\mathrm{OR} 0.70 ; 95 \% \mathrm{Cl}$ 0.58-0.83) than when not counseled. Furthermore, adolescents with achievement/career choice-related and family problems were at a lower risk of suicide ideation/suicide attempts when counseled by their mother or friend than when they received no counseling.

Conclusions: Suicidal ideation/suicide attempts showed different associations for both sexes in accordance with the type of counselor. Even if counseling by specialists for issues such as achievement/career choice-related or family matters is needed, the risk of suicide could be reduced through counseling by the people around them. Therefore, adolescents should form mutually supportive relationships through active communication with surrounding people.

Keywords: Suicidal ideation, Suicide attempt, Counselor, Adolescent, South Korea

\section{Background}

Since 2003, South Korea has had the highest suicide rate per 100,000 people among all member countries of the Organization for Economic Co-operation and Development (OECD); in 2016, 13,092 people $(1.5 / \mathrm{h})$ committed suicide [1]. Suicide is the leading cause of death

\footnotetext{
*Correspondence: ecpark@yuhs.ac

${ }^{3}$ Department of Preventive Medicine, Yonsei University College of Medicine, 50 Yonsei-ro, Seodaemun-gu, Seoul 03722, Republic of Korea

Full list of author information is available at the end of the article
}

in teenagers and young adults in South Korea, accounting for $30.0 \%$ of deaths among those in their $10 \mathrm{~s}, 43.8 \%$ among those in their $20 \mathrm{~s}$, and $35.8 \%$ among those in their $30 \mathrm{~s}$ [2]. Moreover, it has been reported that substantial sex-associated differences exist in suicidal behaviors among adolescents $[3,4]$. The risk factors associated with suicidal behavior are also known to differ between male and female adolescents, as psychiatric problems which affect suicide risk may vary in male and female adolescents [3, 5]. Suicide is, therefore, a serious problem for young people in South Korea. While the suicide rate original author(s) and the source, provide a link to the Creative Commons licence, and indicate if changes were made. The images or other third party material in this article are included in the article's Creative Commons licence, unless indicated otherwise in a credit line to the material. If material is not included in the article's Creative Commons licence and your intended use is not permitted by statutory regulation or exceeds the permitted use, you will need to obtain permission directly from the copyright holder. To view a copy of this licence, visit http://creativecommons.org/licenses/by/4.0/. The Creative Commons Public Domain Dedication waiver (http://creativecommons.org/publicdomain/zero/1.0/) applies to the data made available in this article, unless otherwise stated in a credit line to the data. 
is important to track, suicidal ideation/suicide attempts, which comprise pre-suicide stages, are more meaningful. Adolescents who think about or attempt suicide could be considered a key latent suicide risk group [6]. Preventing suicide in adolescents is, therefore, important because it may help reduce actual suicide related deaths in South Korea [7].

Many studies conducted worldwide have documented the positive effect of counseling on suicide $[8,9]$. That said, the proportion of Korean adolescents who resolve their problems by themselves has risen from $16.9 \%$ in 2010 to $21.8 \%$ in 2016 [10]. One explanation for this is the widespread use of smartphones and improved internet accessibility, thus enabling adolescents to easily find the information they need to deal with their problems independently [11]. We know that the average size of households in Korea has reduced from 5.3 in 1970 to 2.5 in 2016 [11], indicating that the family structure in South Korea has gradually nuclearized. A decrease in the number of family members (parents/siblings) could mean diminished interactions with those whom individuals are most likely to be psychologically dependent upon. Moreover, according to the 2018 survey results of Child Fund Korea, a total of 571 respondents only spent an average of $13 \mathrm{~min}$ a day (on weekdays) with their family [12]. Therefore, we examined the relationship between the existence/types of counselors and suicide in adolescents; thus, this study has implications for suicide prevention.

Although committing suicide and attempted suicide are complex behaviors, they are known to be highly associated with internalizing psychopathology (e.g., depression and anxiety), demographic characteristics (e.g., age), and social factors (e.g., stressful life events) [13, 14]. It has been reported that patients with a history of major depression were more likely to attempt suicide compared to healthy controls [15]. Moreover, stress has been identified as a key determinant of suicidal behavior [13]. Previous studies have shown that the level of perceived stress due to various reasons, such as conflict with family or academic problems, is highly associated with suicidal behaviors [16]. Therefore, in addition to mental health response, a social and public health response is crucial in preventing suicidal behaviors in troubled adolescents [17].

Furthermore, it is necessary to investigate the association of the type of counselor with suicidal ideation and suicide attempts in South Korean adolescents after adjusting for other demographic, socioeconomic, and health-related characteristics. It is practically impossible for all youths who think about or attempt suicide to have access to professionally trained counselors [18]. Given this reality, the purpose of this study was to examine whether suicidal ideation or suicide attempts of an adolescent are associated with a counselor who was in close proximity with the adolescent.

\section{Methods \\ Study population}

The data used in this study were taken from the 2015 Korea Youth Risk Behavior Web-based Survey (KYRBWS) conducted by the Ministry of Education, Ministry of Health and Welfare, and Korea Centers for Disease Control and Prevention (KCDC). The KYRBWS is an annual anonymous online self-reported survey to investigate Korean adolescent health-related behavior. The data collected is used to conduct cross-sectional studies. The KYRBWS was approved by the KCDC Institutional Review Board (2014-06EXP-02-P-A) in 2014. Since 2015, the ethics approval for the KYRBWS was waived by the KCDC Institutional Review Board under the Bioethics and Safety Act and opened to the public. All participants provided informed consent to participate in the KYRBWS and were guaranteed anonymity. The KYRBWS is an anonymous, Internet-based, self-administered structured questionnaire that uses a complex research design, including multistage sampling, stratification, and clustering [19]. The survey comprises 123 questions assessing 15 health-related behaviors. The target population of the survey are students in grades 7 through 12 in South Korea. For each grade level, sample classes are chosen at random from schools across the country, with all students in the selected classes being chosen as the sample students [20]. Given that questions concerning the causes of stress were only included in 2015, we selected this year as the study period. We excluded data from 2558 individuals because of missing responses, and the response rate was $96.7 \%$. As only individuals who had concerns needed a counselor, which was our main interest, we did not include those who reported no stress. Finally, the survey was completed by 65,485 adolescents (male, $\mathrm{n}=33,254,50.78 \%$; female, $\mathrm{n}=32,231,49.21 \%$ ), and they were included in the study.

\section{Variables}

The variable of interest was the type of counselor, which was assessed for each adolescent by asking, "Who do you usually seek counsel from when you have a problem?". The answers were classified into one of the following seven categories: (1) father, (2) mother, (3) sibling, (4) friend, (5) teacher, (6) other, and (7) none.

The dependent variables were suicide ideation and suicide attempts, which were assessed by the two following KYRBWS questions: "Have you seriously considered suicide in the past 12 months?", and "Have you attempted suicide in the past 12 months?". The responses to both questions were either "yes" or "no." 
The covariates were sex, middle/high school, having parents ("father," "step-father," "mother," and "step-mother" responses were re-coded into "both or single-parent family" and "none"), perceived household economic status ("high," "middle-high," "middle," "middle-low," and "low" responses were re-coded into "high", "middle," and "low"), academic achievement ("high," "middle-high," "middle," "middle-low," and "low" responses were re-coded into "high," "middle," and "low"), experience of alcohol/smoking (at least a glass of alcohol/a cigarette, responses to which were yes/no), subjective happiness ("very happy," "happy," "neither happy nor unhappy," "unhappy," and "very unhappy" responses were re-coded into "happy," "neutral," "unhappy"), stress awareness ("very high," "high," "low," and "very low" responses were re-coded into "high" and "low"), depression (ever having experienced a sense of sadness or despair to an extent that daily life was disrupted in the past 12 months, responses to which were yes/no), and sleeping time for fatigue recovery ("very sufficient," "sufficient," "normal," "not sufficient," and "not at all" responses were re-coded into "sufficient," "normal," and "not sufficient"). We regrouped the responses for causes of stress according to the frequency of each category, as follows: "achievement/career choice," "family problems," "friendship relations," "appearance" and "others." Individuals who answered "conflict with parents" and "family environment" were classified as having "family problems." Categories with less than $1 \%$ responses were classified as others. The analysis was conducted according to sex because biological and psychological characteristics differ by sex.

\section{Statistical analysis}

Chi-square tests were used to analyze the general characteristics of the study population. A multiple logistic regression analysis was performed to examine the association between suicidal ideation/suicide attempts and other variables. Subgroup analyses were also performed using multiple logistic regression to examine the associations between types of counselors and suicidal ideation/ suicide attempts stratified by causes of stress for both sexes. The results were reported as odds ratios (ORs) and 95\% confidence intervals (CIs). Statistical significance was defined as $\mathrm{P}<0.05$. All data management and statistical analyses were conducted using SAS software (version 9.4; SAS Inc., Cary, NC, USA).

\section{Results}

Table 1 shows the general characteristics of the study population by sex, which included 65,485 participants (33,254 males, 32,231 females). Of these, 9.7\% $(n=3242)$ of male participants and $14.0 \%(n=4526)$ of female participants experienced suicidal ideation, while $1.9 \%(n=628)$ of male participants and 3.0\% $(n=972)$ of female participants had attempted suicide. Among the male participants, $30.1 \%(n=10,013)$ had no counselors, $28.2 \%(n=9389)$ were counseled by a friend, $24.5 \%(\mathrm{n}=8131)$ by their mother, and $2.6 \%(\mathrm{n}=858)$ by their teacher. Meanwhile, among female participants, $44.2 \%(\mathrm{n}=14,254)$ were counseled by a friend, $29.7 \%$ $(\mathrm{n}=9583)$ by their mother, $13.4 \%(\mathrm{n}=4306)$ had no counselor, and $1.1 \%(n=367)$ were counseled by their teachers.

Among the participants with depression, suicidal ideation was reported in $14.5 \%(\mathrm{n}=2269)$ of male and $21.4 \%$ $(n=3364)$ of female participants, and suicide attempts were reported by $3.0 \%(n=470)$ of male participants and $4.8 \%(\mathrm{n}=757)$ of female participants. Regarding suicide attempts by male participants, all $\mathrm{P}$ values for the proposed variables revealed statistical significance, except for those for middle and high school. Stress was caused by achievement/career choice in $57.5 \%(n=19,123)$ of male participants and $60.7 \%(n=19,576)$ of female participants, family problems in $18.4 \%$ of male and $13.5 \%$ of female participants, and by appearance in $9.5 \%$ of male and $12.4 \%$ of female participants.

The ORs of factors associated with suicidal ideation/ suicide attempts are presented in Table 2 according to sex. Male participants who were counseled by their mother (OR 0.80; 95\% CI 0.70-0.90) or a friend (OR 0.89; 95\% CI 0.80-0.99) were less likely to think about suicide compared to those who had no counselor; those who were counseled by a friend (OR 0.74; 95\% CI 0.60-0.92) were less likely to attempt suicide compared to those who had no counselor. Regarding suicidal ideation in female participants, the ORs of suicidal ideation in all types of counselors were statistically low, except for fathers and teachers. The OR of suicide attempts in female participants who had been counseled by their mother and friend was 0.66 -fold higher (95\% CI 0.53-0.82) and 0.70fold higher (95\% CI 0.58-0.83), respectively, than those of female participants with no counselor. In particular, male and female participants who were depressed had an 8.15 and 6.85 times greater risk of suicidal ideation and a 7.08 and 5.32 times greater risk for attempting suicide, respectively, compared to those without depression. With regard to the causes of stress, male participants were more likely to think about suicide due to problems with their family (OR 1.58; 95\% CI 1.42-1.75) or friends (OR 1.29; 95\% CI 1.12-1.48) than due to achievement/career choice issues. Similarly, female participants were more likely to consider suicide due to problems with their family (OR 1.62; 95\% CI 1.47-1.80) or friends (OR 1.30; 95\% CI 1.16-1.45) than due to achievement/career choice issues. In terms of causes of stress, all ORs for suicide 


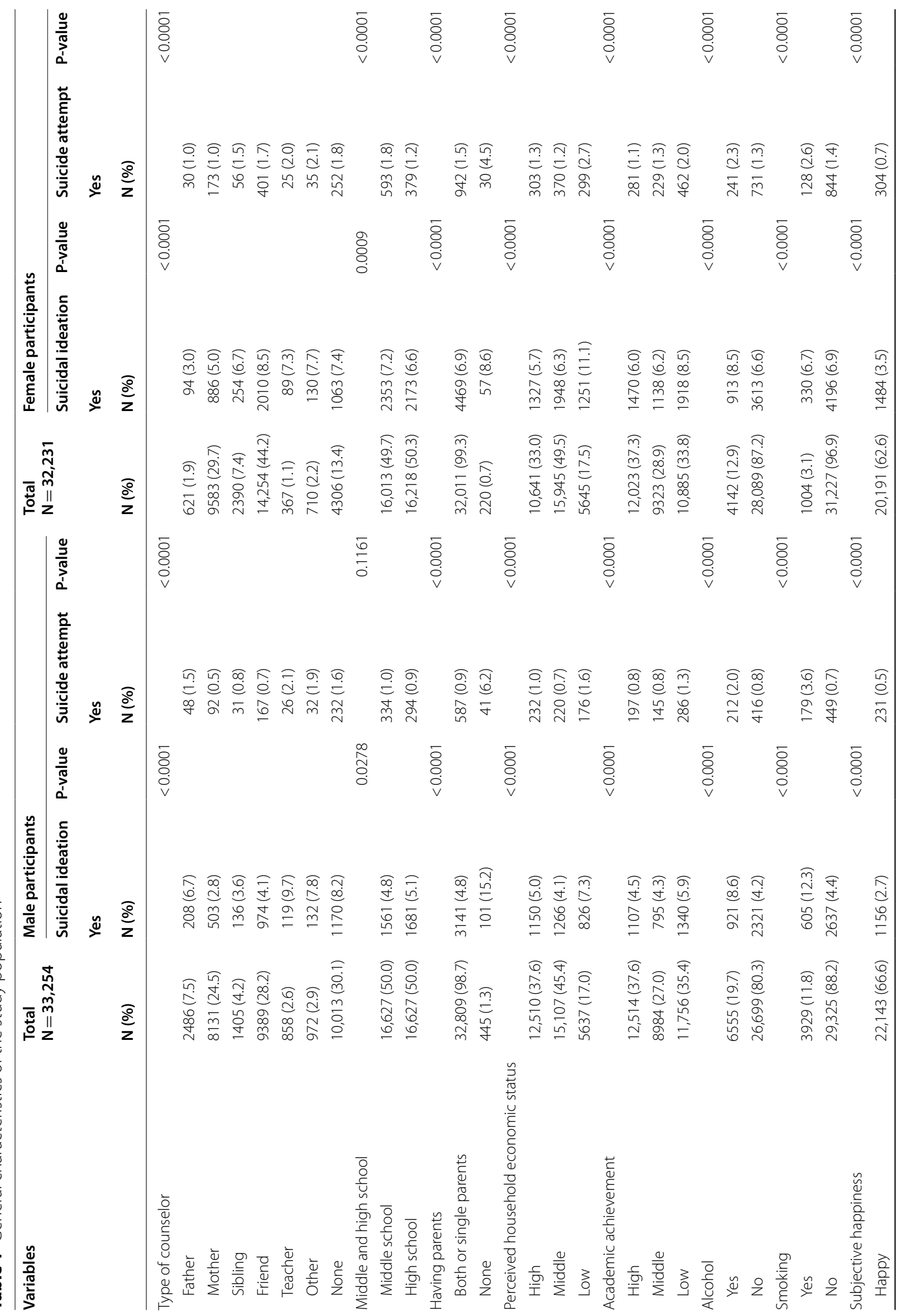




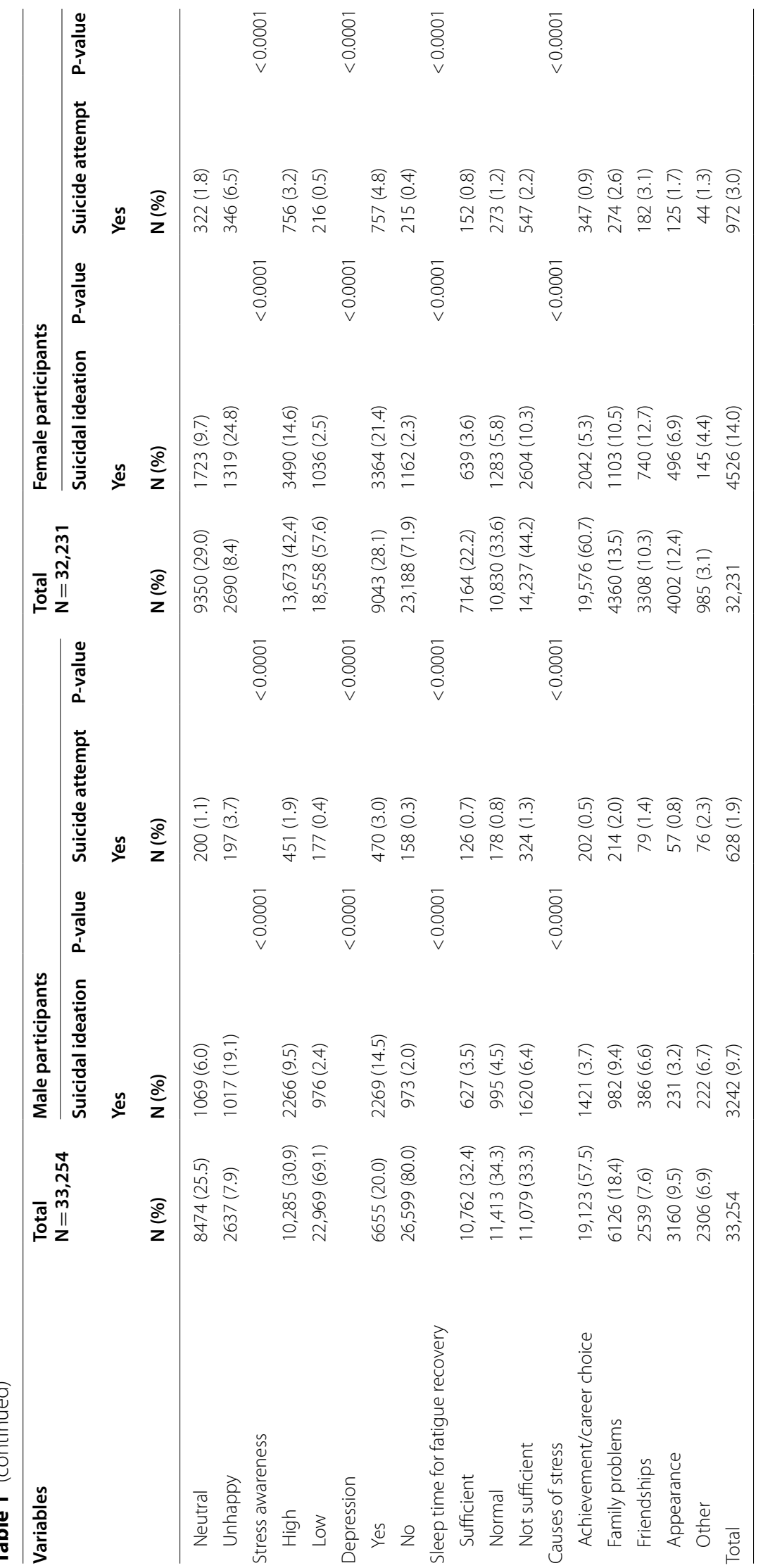


Table 2 Factors associated with suicidal ideation/suicide attempts

\begin{tabular}{|c|c|c|c|c|c|c|c|c|}
\hline \multirow[t]{3}{*}{ Variables } & \multicolumn{4}{|c|}{ Male participants } & \multicolumn{4}{|c|}{ Female participants } \\
\hline & \multicolumn{2}{|c|}{ Suicidal ideation } & \multicolumn{2}{|c|}{ Suicide attempt } & \multicolumn{2}{|c|}{ Suicidal ideation } & \multicolumn{2}{|c|}{ Suicide attempt } \\
\hline & Adj. OR & $95 \% \mathrm{Cl}$ & Adj. OR & $95 \% \mathrm{Cl}$ & Adj. OR & $95 \% \mathrm{Cl}$ & Adj. OR & $95 \% \mathrm{Cl}$ \\
\hline \multicolumn{9}{|l|}{ Type of counselor } \\
\hline Father & 1.03 & $(0.86-1.23)$ & 1.15 & $(0.83-1.61)$ & 0.82 & $(0.63-1.08)$ & 1.20 & $(0.79-1.84)$ \\
\hline Mother & 0.80 & $(0.70-0.90)$ & 0.83 & $(0.64-1.07)$ & 0.61 & $(0.54-0.68)$ & 0.66 & $(0.53-0.82)$ \\
\hline Sibling & 1.01 & $(0.81-1.26)$ & 1.10 & $(0.74-1.65)$ & 0.61 & $(0.51-0.72)$ & 0.74 & $(0.55-1.01)$ \\
\hline Friend & 0.89 & $(0.80-0.99)$ & 0.74 & $(0.60-0.92)$ & 0.69 & $(0.62-0.76)$ & 0.70 & $(0.58-0.83)$ \\
\hline Teacher & 1.16 & $(0.91-1.47)$ & 1.18 & $(0.77-1.82)$ & 0.82 & $(0.61-1.11)$ & 0.95 & $(0.60-1.51)$ \\
\hline Other & 1.25 & $(0.99-1.57)$ & 1.37 & $(0.92-2.04)$ & 0.66 & $(0.52-0.83)$ & 0.91 & $(0.62-1.34)$ \\
\hline None & 1.00 & & 1.00 & & 1.00 & & 1.00 & \\
\hline \multicolumn{9}{|l|}{ Middle and high school } \\
\hline Middle school & 1.30 & $(1.18-1.42)$ & 1.68 & $(1.40-2.02)$ & 1.47 & $(1.36-1.60)$ & 2.06 & $(1.40-2.06)$ \\
\hline High school & 1.00 & & 1.00 & & 1.00 & & 1.00 & \\
\hline \multicolumn{9}{|l|}{ Having parents } \\
\hline Both or single parents & 0.52 & $(0.40-0.68)$ & 0.34 & $(0.24-0.49)$ & 0.90 & $(0.63-1.31)$ & 0.44 & $(0.23-0.50)$ \\
\hline None & 1.00 & & 1.00 & & 1.00 & & 1.00 & \\
\hline \multicolumn{9}{|c|}{ Perceived household economic status } \\
\hline High & 1.00 & $(0.89-1.13)$ & 1.01 & $(0.81-1.26)$ & 0.85 & $(0.77-0.95)$ & 0.97 & $(0.84-1.33)$ \\
\hline Middle & 0.88 & $(0.79-0.99)$ & 0.81 & $(0.65-1.00)$ & 0.74 & $(0.67-0.82)$ & 0.71 & $(0.67-1.05)$ \\
\hline Low & 1.00 & & 1.00 & & 1.00 & & 1.00 & \\
\hline \multicolumn{9}{|l|}{ Academic achievement } \\
\hline High & 1.04 & $(0.94-1.15)$ & 0.93 & $(0.76-1.13)$ & 1.12 & $(1.02-1.23)$ & 0.91 & $(0.71-1.07)$ \\
\hline Middle & 1.04 & $(0.93-1.16)$ & 0.96 & $(0.78-1.19)$ & 0.99 & $(0.90-1.09)$ & 0.94 & $(0.76-1.17)$ \\
\hline Low & 1.00 & & 1.00 & & 1.00 & & 1.00 & \\
\hline \multicolumn{9}{|l|}{ Alcohol } \\
\hline Yes & 1.20 & $(1.07-1.34)$ & 1.23 & $(0.99-1.53)$ & 1.24 & $(1.11-1.38)$ & 1.38 & $(0.95-1.47)$ \\
\hline No & 1.00 & & 1.00 & & 1.00 & & 1.00 & \\
\hline \multicolumn{9}{|l|}{ Smoking } \\
\hline Yes & 1.06 & $(0.93-1.21)$ & 1.87 & $(1.49-2.35)$ & 1.41 & $(1.18-1.68)$ & 2.30 & $(1.49-2.37)$ \\
\hline No & 1.00 & & 1.00 & & 1.00 & & 1.00 & \\
\hline \multicolumn{9}{|l|}{ Subjective happiness } \\
\hline Happy & 1.00 & & & & 1.00 & & 1.00 & \\
\hline Neutral & 1.50 & $(1.36-1.66)$ & 1.24 & $(1.01-1.53)$ & 1.51 & $(1.38-1.64)$ & 1.25 & $(1.05-1.49)$ \\
\hline Unhappy & 3.32 & $(2.94-3.75)$ & 1.92 & $(1.52-2.41)$ & 3.46 & $(3.09-3.88)$ & 2.70 & $(2.23-3.28)$ \\
\hline \multicolumn{9}{|l|}{ Stress awareness } \\
\hline High & 2.43 & $(2.21-2.67)$ & 2.20 & $(1.79-2.69)$ & 2.34 & $(2.15-2.55)$ & 1.91 & $(1.60-2.28)$ \\
\hline Low & 1.00 & & 1.00 & & 1.00 & & 1.00 & \\
\hline \multicolumn{9}{|l|}{ Depression } \\
\hline Yes & 8.15 & $(7.46-8.90)$ & 7.08 & $(5.81-8.63)$ & 6.85 & $(6.33-7.40)$ & 5.32 & $(4.51-6.28)$ \\
\hline No & 1.00 & & 1.00 & & 1.00 & & 1.00 & \\
\hline \multicolumn{9}{|l|}{ Sleep time for fatigue recovery } \\
\hline Sufficient & 0.78 & $(0.70-0.88)$ & 0.79 & $(0.63-0.99)$ & 0.85 & $(0.76-0.95)$ & 0.98 & $(0.80-1.20)$ \\
\hline Normal & 0.92 & $(0.83-1.01)$ & 0.83 & $(0.68-1.01)$ & 0.85 & $(0.78-0.93)$ & 0.90 & $(0.77-1.06)$ \\
\hline Not sufficient & 1.00 & & 1.00 & & 1.00 & & 1.00 & \\
\hline \multicolumn{9}{|l|}{ Causes of stress } \\
\hline Achievement/career choice & 1.00 & & 1.00 & & 1.00 & & 1.00 & \\
\hline Family problems & 1.58 & $(1.42-1.75)$ & 1.91 & $(1.55-2.36)$ & 1.62 & $(1.47-1.80)$ & 1.68 & $(1.41-2.01)$ \\
\hline Friendships & 1.29 & $(1.12-1.48)$ & 1.64 & $(1.25-2.16)$ & 1.30 & $(1.16-1.45)$ & 1.49 & $(1.23-1.82)$ \\
\hline Appearance & 0.95 & $(0.80-1.11)$ & 1.53 & $(1.12-2.08)$ & 1.01 & $(0.90-1.14)$ & 1.30 & $(1.05-1.62)$ \\
\hline Other & 1.10 & $(0.93-1.31)$ & 2.42 & $(1.83-3.21)$ & 1.03 & $(0.83-1.27)$ & 1.51 & $(1.07-2.13)$ \\
\hline
\end{tabular}

Cl confidence interval, $O R$ odds ratio 
attempt were significantly higher compared to that of achievement/career choice for both sexes.

Table 3 shows a subgroup analysis of the associations between the types of counselor and suicidal ideation/suicide attempt stratified by causes of stress for both sexes. Male participants who were counseled by their mothers were less likely to think about suicide when they had achievement/career choice (OR 0.75; 95\% CI 0.63-0.89) or family (OR $0.74 ; 95 \%$ CI $0.57-0.97$ ) problems than participants with no counselor, and those who were counseled by a friend were less likely to attempt suicide when they were experiencing achievement/career choice (OR 0.66 ; 95\% CI 0.45-0.96) or appearance (OR 0.50; 95\% CI 0.25-0.99) problems compared to participants without counselor. On the other hand, female participants who were counseled by anyone except their father were less likely to think about suicide when they had achievement/ career problems than participants without counselor, and those who were counseled by their mother or friend were less likely to attempt suicide when they were experiencing achievement/career choice or friend problems compared to those without any counselor.

\section{Discussion}

In the present study, we used nationally represented data to examine whether having a counselor was significantly associated with suicidal ideation/suicide attempts in adolescents and whether counselor type had an effect. We found that each type of counselor had a different association with suicidal ideation/suicide attempts in both male and female participants. In addition, associations between the type of counselor and suicidal ideation/suicide attempts were significantly influenced by level of education, having parents, subjective happiness, stress awareness, depression, and causes of stress.

We found that female participants tended to have more suicidal thoughts and attempts than males did, which supports previous findings [21-24]. Male participants were more likely than female participants to have no counselors; female participants were mostly counseled by friends. As women tend to actively communicate with those around them, they are perhaps more likely than men to have a counselor; conversely, men in Korea may not be familiar with expressing their difficulties to others, so they may be forced to suppress emotions (such as sadness) [25]. Teachers accounted for the lowest proportion of counselors for both sexes, which is suggestive of a general lack of communication with teachers.

Previous research has reported that psychological stability can be felt through intimate emotional ties with the family during adolescence [26]. Therefore, we hypothesized that finding counsel with one's mother may be the most effective for reducing the risk of suicidal ideations/ suicide attempts. However, we found that the likelihood of suicidal thoughts/suicide attempts was not always the lowest when the counselor was a mother.

The OR for suicidal ideation/suicide attempts was significantly low for both sexes when they were counseled by friends, which suggests that not only family members can prevent suicides but also friends can do the same. Social relationships significantly affect adolescents' physical and mental health; thus, a good relationship with not only family members but also friends could lower the risk of suicidal ideation [27]. Female participants were significantly less likely to experience suicidal ideation when they confided in their family members (except for their father) and another person (including a friend) compared to participants who did not receive any counselling, which indicates that women were more easily psychologically affected by people around them than were men, for whom only counsel from mothers or friends seemed to have significant effects. A previous study showed that adolescent girls typically perceived higher levels of social support from their friends than did boys with similar levels of adult support [28]. However, social support is still important for mental health of both sexes [29]. Regarding suicide attempts, friends may be the most effective in reducing the risk of suicide attempts for male participants, whereas mothers and friends were the most effective for female participants. As adolescents spend most of their time in school, support from their friends might be highly associated with depression and suicidal ideation in both sexes [28].

There was a higher risk of suicide among middle school students than among high school students. We also observed an increased risk of suicide attempts among adolescents in no-parent families than among those with parents. A previous study also showed that adolescents with single-parent families suffer from mental health problems more frequently than do adolescents with twoparent families as the former spend less time with their parents (e.g., having a conversation) that do the latter [30]. Moreover, the risk of suicidal ideation in female participants increased when their academic performance was high. Although both boys and girls have the same levels of worry regarding academic performance, girls are more vulnerable to increased stress due to comparison with their classmates [31]. Moreover, one study showed that adolescent girls experience more stress than boys do [31, 32]. A previous study reported that worries about academic performance among adolescents induces insufficient sleep, as many adolescents believe that academic performance is important for preparing themselves for adulthood [19, 33]. One study showed that adolescents who usually go to bed late due to worries about academic 


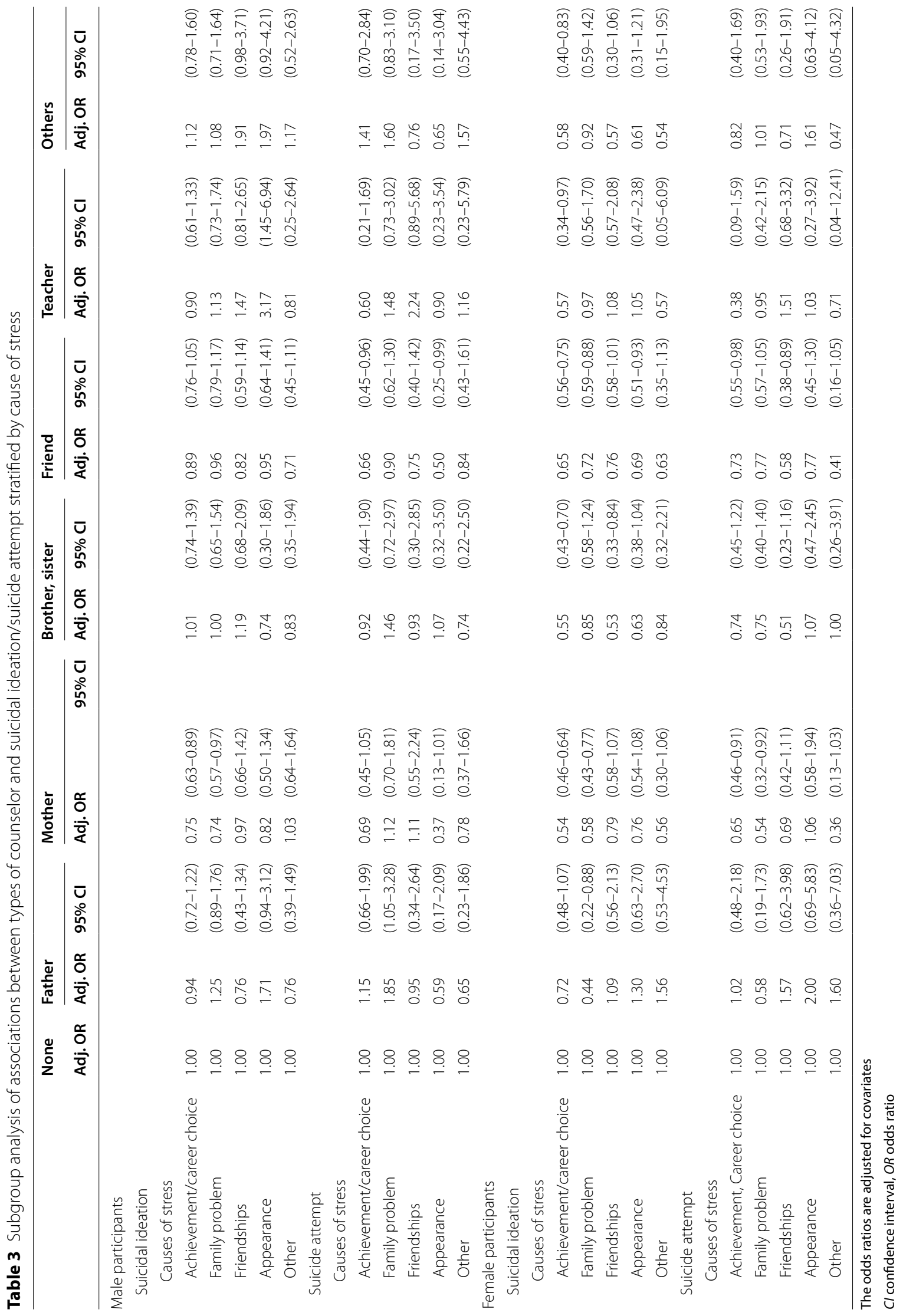


performance in school may have an increased risk of suicidal ideation [19]. Sufficient sleep time in both sexes significantly decreased suicidal ideation compared to insufficient sleep time [19]. This suggests that adequate sleep time can be a good preventive measure against suicide among adolescents.

Overall, risk factors such as subjective happiness, stress awareness, and depression, which have been found to have a significant impact on suicide attempts in previous studies, had lower ORs in those who had attempted suicide than in those who had thought about suicide [34, 35]. This finding can be interpreted in the context of previous studies. Suicide attempts in adolescents tend to occur spontaneously and accidentally, rather than deliberately. This impulsiveness reflects an unstable psychological state rather than a series of continuous processes (think about suicide, make a detailed plan for it, and then attempt or enforce it) [36-38].

We identified differences in the types of counselors who were effective for preventing suicidal ideation/ suicide attempts among male and female participants according to the causes of stress, which significantly reduced the risk of suicide. Adolescents most commonly experienced stress caused by academic performance or career choice anxiety, but the highest risk of suicidal thoughts and suicide attempts was associated with family stress. Stress levels are increased by the burden on the grades and choices of career rather than on itself, which increases the feeling of depression and further causes suicidal thoughts/suicide attempts [39]. In both male and female participants, appearance and other problems were significantly associated with suicide attempts, which suggests that suicide in adolescents is a very complex issue.

The subgroup analysis revealed that male participants were less likely to think about suicide when they were counseled by their mother about family problems compared to those without counselor; however, there was an increased risk of suicide by a factor of 1.85 when they were counseled by their father. A previous study suggested that fathers have difficulties in fulfilling a counselor's role due to a lack of absolute communication time with their children [40]; thus, the risk of suicide in youths is likely to be high when there is a conflict with their fathers in terms of family problems. On the other hand, female participants with a family problem had a significantly reduced likelihood of suicidal thoughts when they were counseled by their fathers, which suggests that fathers can also successfully play a counselor's role. A previous study showed that over half of the girls and one-third of boys felt that they could not be counseled by their fathers [41]. Therefore, the few adolescents who are counseled by their fathers probably have good relationships with their fathers, which may also be related to their low risk for suicidal ideation [41, 42]. Moreover, a previous study showed that depression and suicide are associated with the perceived quality of adolescents' relationships with their parents [43]. Although most Korean adolescents know the necessity of counseling and wish to confide in someone, $88.25 \%$ do not want counseling at school because of the one-sided counseling methods used [44]. In addition, $40.4 \%$ of adolescents in a previous study reported that one-sided counseling was not helpful. However, female participants with achievement/career choice-related problems were less likely to think about suicide when they were counseled by their teacher than when they had no counselor. This suggests that the role of teachers as counselors in preventing suicide should be emphasized, especially considering that adolescents spend most of their time in school and face many academic and career choice problems.

The present study had several limitations. First, as a result of this study's cross-sectional design, cause and effect, as well as the direction of the relationships observed, could not be determined. Second, this study was based on anonymous online surveys, and adolescents may have under- or over-reported characteristics. Therefore, responses could have been affected by social desirability bias. There is a possibility that some adolescents may have expressed their feelings with a desire to let others know about their depression and suffering (stress), which could have affected the study results $[45,46]$. Moreover, as there is a tendency for respondents to show reluctance to answer questions related to suicide, there might have been more people in the sample with suicidal ideation and suicide planning than in the general population. Third, limited information was obtained through the questionnaires. Therefore, it was not possible to examine the interactions between the respondents and their counselors (such as counseling frequency and quality) in more detail. Fourth, the only available results regarding causes of stress were from 2015, and the KYRBWS data for other years could not be obtained. Lastly, due to lack of data, suicidal ideation, suicide attempts, and depression were measured using responses to self-reported dichotomous questions. Therefore, further research using segmented measurements accompanied by experts is needed.

Despite these limitations, the present study has several strengths. To our knowledge, this study is the first to investigate the association between type of counselors and suicidal ideation/suicide attempts. Logistic regression was used to confirm the unique characteristics of South Korean adolescents and their association with suicidal ideation/suicide attempts. Furthermore, as this study analyzed data from the KYRBWS, the results can be generalized to the whole population of South Korean adolescents. The results of this study could be helpful 
for youth mental health promotion and psychological counseling research or be used as basic data for suicide prevention policy development. In addition, the data in this study can be used by youth counseling welfare centers, youth companions (a counseling specialist), or other youth protection services.

\section{Conclusions}

The current study identified a significant relationship between the type of counselor, suicidal ideation, and suicide attempts. Our findings suggest that adolescents who were counseled by family, friends, teachers, or others were less likely to show suicidal ideation and suicide planning than were those who did not receive counseling. Although there was a difference between sexes in relation to the type of counselor that was effective, we found that receiving counseling was beneficial to the mental health of both male and female adolescents. Therefore, our results seem to suggest that it is necessary to lower the communication barriers of adolescents and listen carefully to their worries. As $60 \%$ of individuals transition from suicidal ideation to suicide planning and attempts occur within the first year of the onset of ideation, it is important to prevent suicidal ideation and suicide planning [19]. Furthermore, as having a counselor had a significant influence on suicidal ideation/suicide attempts among adolescents, it is necessary to create an environment in which adolescents can confide in the people around them. Although almost everyone could be a counselor for troubled youths, the effectiveness of each counselor type may vary according to sex. Finally, adults should pay close attention to adolescents, and adolescents need to learn how to form mutually supportive relationships through active communication with those around them.

\section{Abbreviations}

OECD: Organization for Economic Co-operation and Development; KYRBWS: Korea Youth Risk Behavior Web-based Survey; KCDC: Korea Centers for Disease
} Control and Prevention; OR: Odds ratio; Cl: Confidence interval.

\section{Acknowledgements}

We would like to thank the colleagues from the Department of Public Health, Graduate School of Yonsei University, for providing advice on this manuscript. This study was conducted using raw KYRBWS data approved by the KCDC Institutional Review Board.

\section{Authors' contributions}

YK, JY, SAL, and ECP conceived and designed the study. YK and JY performed the study. YK, JY, and SAL analyzed the data. YK, WJ, and ECP drafted the manuscript. YK, WJ, JY, SAL, and ECP edited and provided input for the final manuscript. All authors read and approved the final manuscript.

\section{Funding}

No funding was received for this study.

\section{Availability of data and materials}

The datasets were accessed via https://www.kdca.go.kr/yhs/home.jsp with the approval of the Korea Centers for Disease Control and Prevention (KCDC) after submission of a written oath and data utilization plan.

\section{Declarations}

Ethics approval and consent to participate

The Korea Youth Risk Behavior Web-based Survey (KYRBWS) was approved by the Korea Centers for Disease Control and Prevention (KCDC) Institutional Review Board (2014-06EXP-02-P-A) in 2014. Since 2015, the ethics approval for the KYRBWS was waived by the KCDC Institutional Review Board under the Bioethics and Safety Act and opened to the public.

\section{Consent for publication}

Not applicable.

\section{Competing interests}

The authors declare that they have no competing interests.

\section{Author details}

${ }^{1}$ Department of Public Health, Graduate School, Yonsei University, Seoul, Republic of Korea. ${ }^{2}$ Institute of Health Services Research, Yonsei University, Seoul, Republic of Korea. ${ }^{3}$ Department of Preventive Medicine, Yonsei University College of Medicine, 50 Yonsei-ro, Seodaemun-gu, Seoul 03722, Republic of Korea.

Received: 14 April 2019 Accepted: 26 October 2021

Published online: 06 November 2021

\section{References}

1. Organization for Economic Cooperation and Development. OECD Health Statistics 2017: Mortality_Intentional self-harm. Organization for Economic Cooperation and Development. 2017.

2. Statistics Korea. Annual report on the causes of death statistics in 2016. Daejeon: Statistics Korea; 2017.

3. Park S, Jang H. Correlations between suicide rates and the prevalence of suicide risk factors among Korean adolescents. Psychiatry Res. 2018;261:143-7.

4. Johnson GR, Krug EG, Potter LB. Suicide among adolescents and young adults: a cross-national comparison of 34 countries. Suicide Life Threat Behav. 2000;30(1):74-82.

5. Mazza JJ, Reynolds WM. An investigation of psychopathology in nonreferred suicidal and nonsuicidal adolescents. Suicide Life Threat Behav. 2001:31(3):282-302

6. Shin HJ, Jung IJ, Lee SA, Lee HY, Park JY. Factors affecting depression, suicidal ideation, suicide plans and suicide attempts in adolescence. J Sch Soc Work. 2014;27(1):25-50

7. Reynolds WM. Suicidal ideation questionnaire (SIQ). Odessa: Psychological Assessment Resources; 1987

8. Carney JV, Hazler RJ. Suicide and cognitive-behavioral counseling: implications for mental health counselors. J Ment Health Couns. 1998;20(1):28.

9. Lussier SG. Counselor perspectives on suicide and suicidal ideation: a qualitative study. Gainesville: University of Florida; 2004.

10. Statistics Korea. Statistics on youth 2010. Daejeon: Statistics Korea; 2016.

11. Statistics Korea. Population and housing census. Daejeon: Statistics Korea; 2016.

12. Childfund Korea. Child happy life time. Seoul: Childfund Korea; 2018.

13. vanHeeringen K. Stress-diathesis model of suicidal behavior. Neurobiol Basis Suicide. 2012;51:113.

14. Miller AB, Eisenlohr-Moul T, Giletta M, Hastings PD, Rudolph KD, Nock MK, et al. A within-person approach to risk for suicidal ideation and suicidal behavior: examining the roles of depression, stress, and abuse exposure. J Consult Clin Psychol. 2017:85(7):712

15. Oquendo M, Brent DA, Birmaher B, Greenhill L, Kolko D, Stanley B, et al. Posttraumatic stress disorder comorbid with major depression: factors 
mediating the association with suicidal behavior. Am J Psychiatry. 2005;162(3):560-6.

16. Park S, Lee Y. Factors that affect suicide attempts of adolescents in multicultural families in Korea. Int J Environ Res Public Health. 2016;13(12):1184.

17. Kumar V, Talwar R. Determinants of psychological stress and suicidal behavior in Indian adolescents: a literature review. J Indian Assoc Child Adolesc Ment Health. 2014;10(1):47-68.

18. Ministry of Health \& Welfare. National plan for action on suicide prevention. Sejong: Ministry of Health \& Welfare; 2018.

19. Jeong W, Kim YK, Lee HJ, Jang J, Kim S, Park EC, et al. Association of bedtime with both suicidal ideation and suicide planning among Korean adolescents. Int J Environ Res Public Health. 2019:16(20):3817.

20. Korea Centers for Disease Control and Prevention. The report of the Korea youth risk behavior web-based survey in 2017. Cheongju: Korea Centers for Disease Control and Prevention; 2017.

21. Canetto SS, Lester D. Gender and the primary prevention of suicide mortality. Suicide Life Threat Behav. 1995;25(1):58-69.

22. Range LM, Leach MM. Gender, culture, and suicidal behavior: a feminist critique of theories and research. Suicide Life Threat Behav. 1998;28(1):24-36

23. Westefeld JS, Range LM, Rogers JR, Maples MR, Bromley JL, Alcorn J. Suicide: an overview. Couns Psychol. 2000;28(4):445-510.

24. Laux JM. A primer on suicidology: implications for counselors. J Couns Dev. 2002;80(3):380-3

25. Jung MS, Kim JH. The relationship of male counselor's restricted emotionality, empathic ability, client's working alliance and satisfaction with counseling. Korea J Couns. 2013;14:711-29.

26. Lee EH, Jo YJ. Psychological process of adolescents' suicide: the protecting effects of social support and problem-solving ability. Korea Soc Res. 2008:105-43.

27. Halvorsen JA, Stern RS, Dalgard F, Thoresen M, Bjertness E, Lien L. Suicidal ideation, mental health problems, and social impairment are increased in adolescents with acne: a population-based study. J Investig Dermatol. 2011;131(2):363-70.

28. Fredrick SS, Demaray MK, Malecki CK, Dorio NB. Can social support buffer the association between depression and suicidal ideation in adolescent boys and girls? Psychol Sch. 2018;55(5):490-505.

29. Rueger SY, Malecki CK, Pyun Y, Aycock C, Coyle S. A meta-analytic review of the association between perceived social support and depression in childhood and adolescence. Psychol Bull. 2016;142(10):1017.

30. Sauvola A, Räsänen PK, Joukamaa MI, Jokelainen J, Järvelin M-R, Isohanni MK. Mortality of young adults in relation to single-parent family background: a prospective study of the Northern Finland 1966 birth cohort. Eur J Public Health. 2001;11(3):284-6.

31. Rentala S, Nayak RB, Patil SD, Hegde GS, Aladakatti R. Academic stress among Indian adolescent girls. J Educ Health Promot. 2019;8:158.

32. Anniko MK, Boersma K, Tillfors M. Sources of stress and worry in the development of stress-related mental health problems: a longitudinal investigation from early- to mid-adolescence. Anxiety Stress Coping. 2019;32(2):155-67.

33. Lee YJ, Park J, Kim S, Cho SJ, Kim SJ. Academic performance among adolescents with behaviorally induced insufficient sleep syndrome. J Clin Sleep Med. 2015;11(01):61-8.

34. Cole DA. Psychopathology of adolescent suicide: hopelessness, coping beliefs, and depression. J Abnorm Psychol. 1989;98(3):248.

35. Roberts RE, Roberts CR, Chen YR. Ethnocultural differences in prevalence of adolescent depression. Am J Community Psychol. 1997;25(1):95-110.

36. Park JS, Moon JW. Factors affecting suicidal ideation of the middle and high school students in Korea. Korean Assoc Health Med Sociol. 2010;27(27):105-31.

37. Yang $W Y$, Won HR, Kim JH. Relationship between university examination stress and suicidal thoughts of academic high school students: focusing on the mediating effects of depression. J Korea Inst Youth Facil Environ. 2013;11:59-73.

38. Lee CS, Jung M, Kim YJ. Predictors of suicidal ideation for Korean middle and high school students: the application of decision tree analysis. Stud Korean Youth. 2012;23(1):31-55.

39. Park JY, Chung IJ. The effects of high school students' academic problems on suicidal ideation-focusing on the mediational effects of individual level risk and protective factors. J Korean Soc Child Welf. 2010;32:69-97.

40. Song HR, Ko SK, Park JY, Kwon HJ, Kim YK, Jin MJ. Men's father-role in the context of family friendly environment. Korean Fam Resour Manag Assoc 2010;14(4):341-61.

41. Ackard DM, Neumark-Sztainer D, Story M, Perry C. Parent-child connectedness and behavioral and emotional health among adolescents. Am J Prev Med. 2006;30(1):59-66

42. O'Donnell L, Stueve A, Wardlaw D, O'Donnell C. Adolescent suicidality and adult support: the reach for health study of urban youth. Am J Health Behav. 2003:27(6):633-44.

43. Consoli A, Peyre H, Speranza M, Hassler C, Falissard B, Touchette E, et al. Suicidal behaviors in depressed adolescents: role of perceived relationships in the family. Child Adolesc Psychiatry Ment Health. 2013;7(1):8.

44. Kang YB. A study on the living conditions and perception of a school counseling in high school Seoul. Hankuk University of Foreign Studies. 2001.

45. Song $\mathrm{IH}$, Kwon S, Kim H. The effect of health promoting behavior on suicidal ideation among adolescents: analysis of the mediating effect of self-efficacy. Korea Youth Res Assoc. 2013;20(9):97-123.

46. Song IH, Kwon SW, Jung EH, Kim LJ. Self-efficacy as a mediator on the relationship between parent-child bonding and suicidal ideation among middle school student. Korean J Psychol. 2011;8:199-217.

\section{Publisher's Note}

Springer Nature remains neutral with regard to jurisdictional claims in published maps and institutional affiliations.
Ready to submit your research? Choose BMC and benefit from:

- fast, convenient online submission

- thorough peer review by experienced researchers in your field

- rapid publication on acceptance

- support for research data, including large and complex data types

- gold Open Access which fosters wider collaboration and increased citations

- maximum visibility for your research: over 100M website views per year

At BMC, research is always in progress.

Learn more biomedcentral.com/submissions 